Clinician's Manual on Managing Dyspepsia. G Holtmann, NJ Talley (Pp 96; $£ 7.75)$. London: Science Press, 2000. ISBN 1-85873-376-6.

Picture the scene. An international conference on gastroenterology, delegates flown in from the four corners of the earth, a nice hotel near the sea and golf courses, and one of those keypad voting systems. Dyspepsia? Easy! Dish out a PPI and lets get on to the really interesting stuff like fucosyltransferases and $\mathrm{Ki}$-ras gene point mutations.

But wait! The audience has been asked what it would do with a 43 year old man with an 18 month history of vague upper abdominal pain, a stressful life, and a variable response to $\mathrm{OTCH}_{2}$ blockers. The voting screen reveals an astonishing divergence of opinion about management. A Helicobacter pylori test followed by endoscopy if positive? Plenty of PPI and symptomatic review in a couple of months? Urgent or once in a lifetime endoscopy? The Austrian delegation are muttering about psychotherapy and a shady group of surgeons in the corner are all for an exploratory laparotomy.

This is why people keep writing books about dyspepsia and why this book by Gerald Holtmann and Nick Talley is particularly welcome. It succeeds in combing Germanic thoroughness and a degree of didacticism with clarity of thought and a healthy scepticism about what passes for the "literature". The book has clearly been sponsored by Byk Gulden who make pantoprazole because one of their staff has written the preface. However, the authors are scrupulous and objective about their references to individual drugs, and there is nowhere a hint of commercial bias.

The arrangement of the material is traditional but contains some little gems. The section on the definition and clinical presentation of abdominal syndromes includes very helpful information about subgroups of dyspepsia categories and ways of distinguishing between functional dyspepsia and irritable bowel syndrome. The epidemiology is, as you would expect, thorough, and the chapter on the pathophysiology of functional dyspepsia, supported by almost 100 references, is a mine of information with implications for research as well as clinical practice. There is a good section on psychosomatic factors, once again well referenced and reasonably up to date. The chapters on diagnosis and management also cover most of the recent publications but although the cisapride problem is acknowledged, the recent work on a Helicobacter pylori test and treat strategy from Bytzer's group did not quite get in. There is a terrifying looking algorithm on the management of dyspepsia which, on closer inspection, turns out to be perfectly sensible. Two randomised controlled trials of herbal medicines in the treatment of dyspepsia are referenced. The section on psychological treatment is short but contains an invaluable table describing the basis of the therapeutic relationship between patient and physician.

There is something here for everyone. The family physician will have to be selective but will find useful guidance on diagnostic and management approaches. Trainees in gastroenterology will find the book stimulating and might well start asking some new research questions about dyspepsia. Established gastroenterologists will need to read this book on the plane when they are next subjected to scrutiny on the Costa del Golf.

R JONES
Clinician's Manual on Management Issues in Gastro-esophageal Reflux Disease. Edited by JJ Misiewicz (Pp 66; illustrated; £11.95) UK: Science Press. ISBN 1-85873-353-7.

I started reading this book not entirely sure whose bookshelf it was designed to be placed on. It is written largely by mainland European gastroenterologists, with one American contribution, and most contributors will be unfamiliar to British readers. The first chapter gets off to an inauspicious start, being in a very stilted language style and giving a rather simplistic overview. The use of various reflux terms is not clear and there seems a surprising statement about the lack of utility of 24 hour $\mathrm{pH}$ studies in endoscopy negative reflux patients. In addition, no mention is made of the Dentsleeve catheter in the manometry section, which is an oversight in view of the fact they are discussing LOS relaxation. Thankfully the content and presentation improve dramatically after chapter 1, giving a very useful and informative book on the subject which can be appreciated at all levels of medical training. Specialist registrars will probably find it most helpful as consultants may wish for something a bit more "meaty".

There is a clear concise chapter on short term management, with useful supplementary information and good references, but I detect a slight commercial bias with the PPI recommendations, which is unfortunate as this is clearly a sponsored publication. Long term management is up to date, with even a discussion on the recent conflicting views on Helicobacter pylori and proton pump inhibitors, coming down, rightly in my view, on the side of non-eradication. There is a useful summary of the Genval workshop with two clear flowcharts and some specific recommendations on treatment strategies and dosages, which I found particularly helpful. Interestingly, in the "Special management problems" chapter, a different author gives a completely different viewpoint on the Helicobacter pylori/proton pump inhibitor debate, which adds a bit of spice. There is a sensible summary of non-cardiac chest pain and clear guidelines on drug treatment of reflux disease in pregnancy. Within the confines of a very short chapter, Barrett's is sensitively handled, as well as other complications of reflux disease, and in the final chapter the indications for surgery are discussed. There follows a description of surgical techniques, including laparoscopic fundoplication, and a detailed analysis of short and long term complications. Overall, this book packs a fair amount into its diminutive size and is sensibly priced. It deserves to be widely read.

\section{A IRELAND}

Recent Advances in Coloproctology. Edited by J Beynon, ND Carr (Pp182; illustrated; $\quad £ 80 / \$ 149)$ Germany: Springer-Verlag, 1999. ISBN 1-85233-169-0.

This book addresses 10 topics in which there has been significant development over the past decade. The subjects discussed are diverse, ranging from the combined surgical treatment for advanced pelvic malignancy to incontinence surgery, and from imaging of the anal canal and rectum to the management of anal fissure.
All topics have dual authorship with the exception of the useful chapter on legal matters by PF Schofield. These authors are all UK based apart from MR Salum and SD Wexner (Cleveland Clinic, Florida).

Do you have comprehensive answers to the following questions? If yes, do not read this book!

Question 1. What surgical procedures are now possible for the elderly unfit patient in whom you have just discovered a small malignant rectal polyp?

The outstanding chapter by Cook and McC Mortensen (John Radcliffe Hospital) on transanal endoscopic microsurgery describes this recent advance eloquently. There is an unusually large number of good illustrations and tables in this chapter which cover all aspects of this minimally invasive technique.

Question 2. What's the latest on troublesome haemorrhoids?

The chapter by EA Carapeti and RKS Phillips (St Mark's Hospital) on the treatment of haemorrhoids is very thorough, ending by focussing on the perioperative care package that has made day case surgery possible. The goal posts really have moved since the days of lengthy inpatient care for all.

Question 3. So doctor, what is the chance that this pouch surgery will work?

Are you up to date on the extensive knowledge that has been gained over the past 15 years on complications and long term outcome of pelvic pouch surgery? In the UK, none has performed more first time pouches nor has anyone as great an experience in revisional pouch surgery as John Nicholls, who addresses this topic.

Question 4. Is laparoscopic colorectal surgery here to stay? What are the indications for it and is there any evidence that it is better than open surgery?

Interestingly, the editors decided to look further afield for the answers in this controversial area.

Coloproctology is the most popular subspecialty among general surgical trainees. One reason for this is that it is a specialty on the move. There are recent advances in many other areas left for future editions of this book: management of acute colitis, colonic stenting, training, the input of colorectal nurse specialists, to name a few. I hope these future editions will also have input from gastroenterology, nursing, oncology, and radiology. After all, the editors acknowledge in the preface that coloproctology has now been transformed from a purely surgical to a multidisciplinary specialty.

The reputation of the colorectal unit at Singleton Hospital (where the editors are based) will certainly be further enhanced by this well collated and useful book.

A LEATHER

Errors occurred in the UEGW abstracts supplement Gut 2000;47(suppl III). For abstracts A136 and A160, the complete author list for both abstracts is $\mathrm{M} \mathrm{M}$ Diculescu, E M Ionescu, M Ciocirlan, $M$ Prunescu, R Iacob, S Iacob, C Apetrechioaie, A Oproiu. For abstract A271, the complete author list is H J Tan and D G Nasmyth. 